\title{
Configurações
}

Revista Ciências Sociais

$10 \mid 2012$

Políticas Públicas

\section{Atividades de enriquecimento curricular: 0 difícil equilíbrio entre a resposta social e a qualidade educativa}

Curriculum Enrichment Activities: The difficult balance between the social response and quality educational

Activités d'enrichissement Curriculum : le difficile équilibre entre la réponse sociale et qualité de l'éducation

\section{Ana Mouraz, Ana Vale e Jorge Martins}

\section{OpenEdition}

\section{Journals}

\section{Edição electrónica}

URL: http://journals.openedition.org/configuracoes/1438

DOI: $10.4000 /$ configuracoes. 1438

ISSN: 2182-7419

\section{Editora}

Centro de Investigação em Ciências Sociais

\section{Edição impressa}

Data de publição: 1 dezembro 2012

Paginação: 123-136

ISBN: 1646-5075

ISSN: 1646-5075

\section{Refêrencia eletrónica}

Ana Mouraz, Ana Vale e Jorge Martins, « Atividades de enriquecimento curricular: O difícil equilíbrio entre a resposta social e a qualidade educativa », Configurações [Online], 10 | 2012, posto online no dia 17 fevereiro 2014, consultado o 10 dezembro 2020. URL : http://journals.openedition.org/ configuracoes/1438; DOI : https://doi.org/10.4000/configuracoes.1438 


\title{
Atividades de enriquecimento curricular: 0 difícil equilíbrio entre a resposta social e a qualidade educativa
}

\author{
Curriculum Enrichment Activities: The difficult balance between the social \\ response and quality educational \\ Activités d'enrichissement Curriculum : le difficile équilibre entre la réponse \\ sociale et qualité de l'éducation
}

Ana Mouraz, Ana Vale and Jorge Martins

\section{Introdução}

1 Em Portugal, a escola a tempo inteiro (ETI) foi generalizada em 2006/07, um pouco antes de ter ocorrido a enorme crise financeira ${ }^{1}$ que viria a alterar significativamente o modo como, nas sociedades ocidentais, as políticas públicas procuravam alcançar o bem comum.

Desde então, o programa de Atividades de Enriquecimento Curricular (AEC), desconcentradamente dirigido ao $1^{\circ}$ Ciclo da escola pública, tem constituído um instrumento político relevante na concretização daquela finalidade, através da oferta gratuita de atividades enriquecedoras do currículo da educação básica - que, sem essa oferta, não chegariam a todas as crianças por razões de custo - e da criação de respostas sociais de apoio às famílias, nomeadamente o serviço de guarda das crianças após o seu horário letivo.

3 A reflexão aqui apresentada, para além de equacionar o alcance das medidas políticas implementadas em 2009/2010 no âmbito do programa, procura clarificar o estado de “equilíbrio" entre as duas finalidades. $\mathrm{Na}$ análise, tivemos em conta as duas dimensões centrais da operacionalização do programa: por um lado a dimensão política, que se prende com as decisões, as justificações e o modo como o programa foi implementado, e, 
por outro lado, a curricular, que questiona o conceito de ETI e convoca a dialética currículo formal/ informal. Esta reflexão sustenta-se na empiria resultante de um estudo multicasos, cuja apresentação não é o objetivo deste texto².

\section{O Programa AEC como política pública de cariz social num contexto de transição}

4 No contexto do aprofundamento da complexa crise instalada em Portugal, que tem conduzido ao questionamento do papel do Estado (Bateira, 2011), o programa tem vindo a afirmar-se como um exemplo significativo do novo modo de prestação do serviço público educativo, realizado através de "contratos de ação pública".

5 Inicialmente desenhado por um governo socialista (2005-2009) como um instrumento da política europeísta de modernização do país, o programa pretendia promover a aprendizagem precoce da língua inglesa no $1^{\circ}$ ciclo $^{3}$. Esta era a estratégia para o sistema educativo português ter os "padrões europeus" no que respeita à "elevação do nível de formação e qualificação das futuras gerações" e para promover "o desenvolvimento precoce de competências, no quadro da crescente mobilidade de pessoas no espaço da União Europeia". Este movimento é um dos aspetos que caracteriza a influência transnacional e europeizante nas políticas educativas portuguesas (Pacheco e Vieira, 2006). Todavia, ainda sem as pressões austeritárias produzidas pela crise da dívida que iria manifestar-se em 2011, bem depressa a generalização do ensino de inglês nos $3^{\circ}$ e $4^{\circ}$ anos do $1^{\circ}$ ciclo se alargou e converteu, pelas diversas dinâmicas autárquicas, no programa global que hoje conhecemos.

6 É hoje mais claro que aquela lógica de contratualização, baseada num serviço desconcentrado por contratos entre o ME e os municípios e por subcontratos entre estes e outras entidades públicas e privadas, mostra-se cada vez mais vulnerável aos condicionalismos de um mercado educativo que pretende ocupar o espaço pouco a pouco abandonado pelo Estado. Ao mesmo tempo, como consequência de crescentes limitações orçamentais e da desregulação produzida pela imensa variedade de entidades promotoras e operacionais existentes no terreno, vão-se registando alterações determinantes na gestão curricular, na organização pedagógica e até na arquitetura funcional do $1^{\circ}$ ciclo do ensino básico.

7 É conveniente esclarecer que, em Portugal, a ação desconcentrada se distingue da ação descentralizada em virtude da diferença entre a competência e/ou a capacidade decisória dos poderes em presença (central e local). Na segunda, o poder decisório é transferido da administração central para a local. Já uma ação desconcentrada não pressupõe a transferência de poder, mas apenas a sua execução (Formosinho, 1999).

8 Mas se a entrada do mercado na oferta pública de AEC se manifesta já pelo aparecimento de estratégias locais (e, nalguns casos, também nacionais) de competitividade, produtividade e empreendedorismo tão do agrado do "espaço europeu de educação básica" ${ }^{5}$, é interessante verificar que, por outro lado, as alterações no $1^{\circ}$ ciclo, que acompanharam a universalização das AEC, tendem a relegar para segundo plano a igualdade de oportunidades educativas e a acentuar o cariz social do programa.

De facto, o programa introduzido comportou mudanças significativas na oferta de educação básica, desde logo: $i$ ) a introdução do conceito de enriquecimento num currículo "velho" e em crise; ii) a reformulação das finalidades do $1^{\circ}$ ciclo no quadro de uma 
pretendida continuidade pedagógica proporcionada pelos agrupamentos de escolas; iii) a flexibilização de horários escolares, quer do regime normal quer dos duplos; iv) o recrutamento de novos perfis profissionais para trabalhar com as mesmas crianças no mesmo espaço-aula; v) a nova relação que estes estabeleceram com o funcionamento concreto das escolas e agrupamentos; vi) a divisão de tarefas educativas que passou a ter lugar entre a administração central, as autarquias e as escolas. Porém, o programa ganhou raízes sobretudo na esfera social. Tal aconteceu não só porque veio dar respostas a problemas de gestão do dia a dia de muitas famílias, através da sua reconfiguração como programa ETI, mas também porque veio democratizar o acesso a algumas vantagens educativas que só estavam ao alcance de certas camadas sociais. Ao mesmo tempo, inovando, o programa permitiu compatibilizar a promoção dessa aparente igualdade de oportunidades educativas com as diferentes propostas curriculares vindas das diversas entidades promotoras, procurando responder, assim, ao interesse desencadeado nas comunidades locais.

Apesar de algumas críticas da ANMP, que retomam a discussão sobre as condições de operacionalização da medida, o programa assenta na forte implicação dos Municípios. É sobretudo o gradual reconhecimento jurídico da importância social adquirida pela intervenção educativa autónoma destes que leva o Estado a entregar-lhes a responsabilidade pela oferta do enriquecimento curricular.

11 Pela primeira vez, foram integradas no currículo do $1^{\circ}$ ciclo, "disciplinas" escolhidas pelas entidades promotoras (municípios, associações de pais e agrupamentos) de entre um conjunto de grandes áreas consideradas relevantes na promoção do sucesso e, por isso, financiadas pelo ME. Essas "disciplinas" têm "orientações programáticas", materiais de apoio, horários e professores próprios (PPAEC), definidos pelos promotores, como se fossem verdadeiras disciplinas curriculares. Estamos assim perante um tipo de descentralização educativa que se manifesta na primeira e mais significativa reconfiguração da velha relação entre os dois poderes que tutelavam o $1^{\circ}$ ciclo. Apesar de haver abertura às instituições e entidades locais de um domínio que até agora tinha sido exclusivo da administração central, assiste-se à (re)monopolização dos serviços educativos no espaço escolar (Pires, 2011) ou seja, a componente de apoio à família, que o programa assume, tem como característica central o aumento do tempo passado pelas crianças em ambiente escolar, em atividades lúdicoeducativas. As implicações deste prolongamento de funcionamento das escolas do $1^{\circ}$ ciclo obrigaram ao desenvolvimento de novos equipamentos, de novos recursos físicos e humanos.

Ora, é precisamente aqui que se revelam as virtudes sociais do programa: a progressiva universalização das AEC retirou tempo e espaço para as ofertas promovidas pelos ATL privados, incluindo os promovidos pelas associações de pais e pelas IPSS, ou municipalizados e, assim, o programa configurou-se como uma resposta social para todas as famílias, independentemente dos seus recursos, para a ocupação segura, vigiada e educativa, das crianças do $1^{\circ}$ ciclo durante a jornada de trabalho ou ocupação dos pais.

\section{O programa AEC como política pública de inovação curricular}

13 As AEC pretendem cumprir o duplo objetivo de garantir a todos os alunos do $1^{\circ} \mathrm{Ciclo}$, de forma gratuita, a oferta de aprendizagens enriquecedoras do currículo, ao mesmo tempo 
que se concretiza a prioridade, enunciada pelo governo, de promover a articulação entre o funcionamento da escola e a organização de respostas sociais no domínio do apoio às famílias. Assim, alargam-se os tempos de permanência dos alunos nas escolas, tentando garantir que estes sejam pedagogicamente ricos e complementares das aprendizagens associadas à aquisição de competências básicas.

Desta descrição breve das intencionalidades subjacentes das AEC e dos modos da sua operacionalização sobressaem dois conceitos que importa revisitar: o conceito de ETI e o conceito de currículo informal.

O primeiro conceito define-se, direta ou indiretamente, "pela ocupação educativa dos alunos, de forma plena, ao longo do tempo escolar e no espaço escolar" (Pires, 2007:78). Correspondendo a uma alteração significativa do tempo de aprendizagem e dos agentes que devem preocupar-se com a sua definição, o conceito desafia o que deve entender-se por escolaridade.

16 A ETI é uma resposta aos desafi os que, em Portugal, a escola de massas trouxe ao sistema e que antes ainda não tinham sido experienciados, nomeadamente a constatação de que esta deve preocupar-se em assegurar a justiça social. Ter na escola todas as crianças implica pensar se o que lhes será ensinado, e como, servirá os desígnios (e que desígnios?) da educação providenciada pelo Estado (Leite, 2002). A mesma preocupação torna-se ainda mais premente no tempo presente, em que os discursos políticos usam a bandeira da qualificação como forma de atingir as metas de 2015 para a Educação e de contribuir para a Europa do conhecimento, definida na agenda de Lisboa.

$\mathrm{O}$ conceito anda frequentemente associado a uma finalidade igualitária, porquanto se visa assegurar iguais oportunidades de educação para todas as crianças (Dobert et al., 2004; OCDE, 2007). Assim, interessa assegurar que a " igualdade real e efetiva tem que oferecer oportunidades adequadas e diferenciadas para que cada estudante, sejam quais forem os seus pontos de partida, suas necessidades e circunstâncias, possa alcançar as aprendizagens escolares essenciais e não somente os mínimos" (Muñoz, 2005: 17).

Com as AEC estão a seguir-se políticas que têm vindo a ser adotadas noutros países europeus, desde há cerca de vinte anos, com o mesmo propósito de discriminação positiva (Demeuse et al., 2008). Tais medidas têm sido pensadas para que possam resolver ou minimizar alguma desigualdade social e, com isso, contribuir para aumentar os níveis de sucesso dos alunos na escolaridade formal, em concordância com as tendências identificadas pela OCDE na promoção da equidade na educação. "Fortalecer a relação entre a escola e a família para ajudar os pais desfavorecidos e as suas crianças a aprender; providenciar uma forte educação para todos dando prioridade à educação de infância e à escolaridade básica, são dois dos dez passos para assegurar a equidade" (Field et al., 2007: 15).

19 O conceito de ETI assume outras dimensões significativas: não só a ideia de que algumas aprendizagens que a escola providencia, nesse extra tempo, são mais importantes e socialmente mais homogeneizadoras do que atividades que as famílias e as próprias crianças pudessem organizar de per se, mas também a capacidade preventiva de alguma marginalidade de comportamentos a que os alunos, deixados sem a tutela de adultos responsáveis, poderiam dedicar-se.

20 Também neste ponto, a opção das políticas nacionais foi a de valorizar a ação educativa estruturada, quase sempre na escola ou com recurso ao modelo escolar, como acontece com as AEC. 
21 Finalmente o conceito de ETI associa-se ao fenómeno de alguma desresponsabilização dos alunos face à sua tarefa de aprendentes e, pese embora se diga querer promover-se a autonomia dos estudantes, contribui-se, ao invés, para a sua mais prolongada dependência face aos adultos considerados de referência.

22 É nessa dimensão da oferta, que caracteriza a ETI, que faz sentido questionar o conceito de currículo informal, bem assim como as ligações que ele estabelece com outros que ajudam na compreensão da sua densidade teórica, a saber, os conceitos de territorialização, de coerência e de articulação curriculares.

o currículo informal define-se pelas aprendizagens que a escola tem como intenção promover nos seus alunos, que resultam dos valores que enquadram os seus projetos educativos ou a sua identidade como organização educativa, mas que não são alvo explícito de uma instrução formal e de uma avaliação de resultados verificados nos alunos (Pacheco, 1996). A convicção subjacente, partilhada por muitos autores da sociologia crítica do currículo (Forquin, 1993), é que os muros que rodeiam a escola são apenas símbolos de outros muros de controlo social de que a escola se faz veículo. Assim, quando um sistema educativo não se limita a estruturar e definir o currículo formal, mas escolhe e subsidia determinadas escolhas da oferta de ocupação dos tempos livres, está a formatar duplamente a cultura escolar, ao arrepio do que deveria ser a territorialização curricular. Quer isto dizer que, a um tempo, formata a cultura escolar porquanto escolhe um currículo formal, mas também o faz porque, ao substituir-se aos pais na transmissão dos valores que são mais próximos das vivências familiares, deixa cair o princípio de que as aprendizagens devem ser significativas localmente, e depender das agências locais, como a territorialização curricular advoga.

Como refere Leite, "os fundamentos que legitimam a contextualização curricular de nível micro, referem-se às possibilidades de agência local nas tomadas de decisão curricular, numa lógica de territorialização da educação" (Leite, 2005,17). Este conceito assenta na possibilidade que o local e os seus agentes têm de decidir assuntos relativos à educação, de acordo com princípios e interesses que são aí relevantes.

25 Em Portugal, a territorialização curricular tem servido, sobretudo, para justificar ofertas na educação básica de cariz mais compensatório, já que se tem orientado para as ofertas formativas para jovens que têm falhado a escolaridade regular. Servir o propósito do enriquecimento do currículo formal, ou oferecer um conjunto de atividades desportivas e artísticas de cariz mais universalista, tais são as opções que balizam a oferta curricular das AEC.

Parece-nos possível ler nessa diferença indícios de um certo retorno ao movimento do Back to basics. De facto, a prática de manter a pressão sobre as áreas de aprendizagem consideradas mais nobres e mais básicas, disponibilizando mais tempo curricular para a sua aprendizagem, que se constata nos discursos políticos atuais, assim autoriza pensar. Ao remeter para uma área de currículo informal as aprendizagens que estão associadas às expressões, liberta-se tempo curricular para o que é considerado básico. Por isso, hoje, também se considera que a escola a tempo inteiro, e as AEC em particular, são formas de operacionalizar a tendência do back to basics, das literacias fundamentais (leitura, escrita, numeracia, comunicação), remetendo-se para outros tempos do currículo dimensões mais conotados com a consecução de projetos ou a formação de cariz mais humanista. 


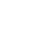
que enformam as decisões curriculares das escolas e resultam quer dos diplomas legais, quer da constatação de que o currículo não pode ser uma soma de partes justapostas.

31 Associado teoricamente à dimensão globalizante do currículo, o conceito tem sido desdobrado em dois vetores que explicitam processualmente como é possível essa totalidade, na perspetiva tanto diacrónica como sincrónica.

Trata-se da articulação vertical ou horizontal.

1. A “articulação curricular vertical está presente na continuidade de níveis/ciclos/anos, na hierarquia das decisões e no equilíbrio das componentes curriculares de formação e sua extensão;

2. A articulação curricular horizontal é observável na correspondência existente no interior de cada unidade e órgão, na transversalidade entre áreas/ disciplinas de um mesmo ano de escolaridade e, ainda, na coerência entre as componentes de operacionalização do currículo" (Leite \& Pacheco, 2010: 6).

Esta articulação adquire a sua sustentabilidade plena em três planos pertinentes: o desenvolvimento dos alunos; o trabalho dos professores e agentes curriculares; a estrutura onde se enquadra politicamente a articulação. São esses três planos que definem o que deve ser entendido como uma boa prática de articulação curricular, isto é, aquela que consegue diagnosticar e intervir em cada escola no lugar de decisão ou de execução curricular onde parece fazer mais falta. Uma boa prática de articulação curricular é, também, a que assegura a coerência curricular, centrada no alinhamento curricular e tornando-a comum ao sujeito coletivo que a põe em prática - os professores que, ao longo do tempo, vão trabalhando com um mesmo aluno. Por extensão da razão anterior, uma boa prática de articulação curricular é a que valoriza a disponibilidade dos professores para trabalharem colaborativamente com os seus pares. 


\section{Caracterização da oferta local} enriquecedoras do currículo, a finalidade igualitária do programa. A forma como esta tem vindo a ser interpretada e traduzida em ações pelo ME, promotores e agentes locais, tem suscitado preocupações e mesmo contestação. A questão centra-se presentemente no como assegurar, a todas as crianças sem exceção, oportunidades de aprendizagens efetivamente enriquecedoras do currículo e, em simultâneo, garantir-lhes uma educação de qualidade. 

a escola e com o saber, bem como nas representacões dos pais, legitimam essas dúvidas e apreensões. Entre eles, destaca-se o alargamento da oferta escolar para 8 horas diárias, cinco de currículo formal mais três de enriquecimento curricular. Ou seja, a redefinição da «temporalidade intraescolar», responsável por algumas alterações muito significativas na gestão das escolas: entre outras, a criação de períodos de prolongamento, a guarda de alunos no intervalo entre o final do tempo letivo e o início das AEC e a oferta de refeições no período do almoço. Alterações que, associadas à redução do pessoal auxiliar da ação educativa, se revelaram potenciadoras de conflitos entre os alunos e geradoras de uma certa anomia.

No mesmo sentido inclui-se a introdução do, aparentemente benéfico, "Apoio ao estudo" para todos os alunos sem exceção. Atividade que, na prática, veio alargar a componente letiva do horário dos PTT e reduzir a sua componente não letiva- um tempo imprescindível à planificação de aulas, à preparação de materiais e essencial ao trabalho colaborativo entre pares. Embora a redução da componente não letiva do horário não seja o único fator impeditivo do trabalho colaborativo, na falta de outras condições objetivas legitima a indisponibilidade dos professores para aderir "à boa prática de articulação curricular" que esta medida veio relevar.

A implementação das AEC (re)colocou no centro do debate educativo o tema da articulação curricular, na sua dupla dimensão horizontal e vertical, sem que contudo, tenham sido criadas as condições mínimas necessárias, tanto do ponto de vista objetivo como subjetivo dos intervenientes, para a sua realização. Falar de condições significa, entre outras coisas, falar da reforma dos currículos, da revisão de horários de PTT/PPAEC e da passagem do tradicional regime de monodocência, que caracteriza o $1^{\circ}$ ciclo, para um "regime oficioso" de ensino coadjuvado7.

Pese embora os responsáveis pela administração das escolas e os PTT reconheçam a pertinência da dimensão social do programa e o potencial das AEC no desenvolvimento pessoal e social das crianças, simultaneamente, identificam um conjunto de efeitos negativos na relação dos alunos com a escola, ao nível dos comportamentos e atitudes, mas sobretudo na relação com o saber escolar, nomeadamente:

i. Fadiga gerada pelo excesso de horas de escolarização, ou híper escolarização das crianças e respetivas consequências no processo de ensino/aprendizagem, tais como perda de atenção, desinteresse e desmotivação dos alunos para aprendizagens curriculares complexas e/ou menos lúdicas;

ii. Desinteresse de alguns alunos pelas atividades curriculares em geral;

iii. Anomia e perda de regras com potenciais repercussões nas atividades curriculares formais;

iv. Redução, quase anulação, de tempo para o trabalho individual/estudo e consequente diminuição do aproveitamento escolar;

v. "Pedagogização do lazer", redução signifi cativa do tempo de jogo/brincadeira das crianças, o que só por si comporta o risco de provocar a saturação de escola.

O ME, até hoje, nunca realizou ou encomendou uma avaliação sistemática dos efeitos das AEC na progressão das aprendizagens dos alunos. Por estranho que pareça, prescindiu de um dos instrumentos essenciais de validação desta política pública educativa. Este quadro torna abusiva toda e qualquer defesa da (in)existência de benefícios - seja ao nível da aquisição de conhecimentos, seja ao nível do desenvolvimento de competências - por se tratar de uma avaliação meramente "impressionista". No entanto, consideramos que 
aqueles efeitos não podem, nem devem, ser desvalorizados, antes carecem de aprofundamento.

Os pais, sobretudo os dos grupos socioeconómicos mais desfavorecidos, apesar de não terem papel ativo na implementação da ETI, valorizam o programa e, sobretudo, a gratuitidade da inscrição nas $\mathrm{AEC}$, a oferta de almoço, bem como a criação dos períodos de prolongamento na guarda das crianças, ou seja, as dimensões sociais do programa. Não obstante, na generalidade dos casos, desenvolveram com as AEC uma relação marcada pela indiferença, que se traduz numa certa desvalorização das atividades, dos respetivos docentes e do regime de funcionamento do período não letivo - desvalorização que é legitimada e reforçada pela falta de influência das atividades na avaliação final e nos percursos escolares dos alunos.

Por último, a introdução das AEC contribuiu para alterar a relação dos pais com a escola, o mesmo é dizer, para alterar o modo como percecionam a instituição escolar e o trabalho dos seus profissionais, em particular os PTT. Esta dimensão necessita de maior aprofundamento, mas é evidente que os pais, através deste programa, passaram a poder comparar áreas de saber e metodologias de ensino e aprendizagem letivas e não letivas.

\section{Reflexões Finais}

O PAEC foi criado com as finalidades expressas de promover a melhoria da qualidade das escolas do $1^{\circ} \mathrm{CEB}$ e das aprendizagens dos alunos, bem como a organização de respostas sociais no domínio do apoio às famílias. Se esta última finalidade foi conseguida, a primeira é muito questionável.

A unânime valorização da filosofia e objetivos do programa constitui uma clara evidência de que este configura, para a maioria dos atores envolvidos, em particular os pais, "uma boa medida" de políticas publicas de educação. Todavia, a eficácia desta política depende de um conjunto de fatores que ainda não estão resolvidos e/ou consolidados.

Entre estes destaca-se a articulação entre professores do $1^{\circ}$ ciclo e o dispositivo técnico que no terreno o implementa e avalia, nomeadamente a articulação curricular que continua a registar níveis de concretização pouco satisfatórios. Este é um dos pontos fracos do programa mais referido. A maioria dos PTT/ PPAEC, bem como as escolas em geral, valorizam discursivamente a articulação curricular (uma das suas competências formais) e consideram-na importante, mas reconhecem que, na prática, não tem sido sufi ciente.

51 Por outro lado, o facto de a oferta das atividades ser obrigatória, mas a frequência não o ser, constitui um fator de instabilidade. No caso da Iniciação ao Inglês, esta incongruência potencia desigualdades na aprendizagem da língua que acabarão por se manifestar na transição para o $2^{\circ}$ ciclo. A solução deste problema, já assinalado por Madureira (2011), passaria pela integração desta atividade no currículo escolar.

Outro fator importante consiste nos mal-entendidos quanto às finalidades das atividades, resultantes da sobreposição, no espaço escolar, das dimensões formal e não formal da educação. Se atentarmos na terminologia utilizada por parte dos atores envolvidos no programa - aulas, alunos, turmas, professores, compêndios, material didático, avaliação concluímos que, tanto para pais como para a generalidade das crianças e os próprios PTT /PPAEC, a especificidade das AEC ainda está por identificar. A ausência de debate e cabal 
esclarecimento desta questão tem contribuído não só para a desvalorização das atividades por parte dos pais, mas também por parte dos PTT.

Não menos polémico é o fator relativo ao tempo e ao seu uso. Como assinala Roldão (2008), quando as AEC preenchem todo o tempo livre dos alunos podem provocar uma pressão insustentável e inadmissível para as crianças (Roldão, 2008). Os promotores detêm a possibilidade de realizar uma boa gestão do tempo e proceder à diferenciação curricular, através da seleção da oferta que melhor se adapte às necessidades locais e à resolução de problemas sentidos pela respetiva comunidade. Contudo, constata-se que, na maioria dos casos, o planeamento da oferta é condicionado pelo tipo de financiamento oferecido.

Articulado com o fator anterior surge a fadiga gerada nos alunos pela prolongada permanência num mesmo espaço, a sala de aula. Esta está na génese de um conjunto de propostas feitas pelos pais com vista a evitar o recurso excessivo ao modelo escolar e minimizar o cansaço das crianças. Segundo estes, as atividades deveriam, por um lado, funcionar em ateliês e oficinas locais, rentabilizando os recursos educativos existentesmodalidade que se aproxima do conceito de cidade educadora (Bernet, 1999). Por outro, contemplar visitas a exposições, audição de concertos e participação noutros eventos culturais, de modo a evitar a guetização das crianças e a superar a pobreza espacial e cultural do seu mundo de origem - uma ideia defendida por Olga den Besten (2010). Contrariamente ao ocorrido noutras experiências e localidades europeias (Schnitter e Haselhoff, s/d e Reh, S. et al., 2011), tais propostas, entre nós, não tiveram acolhimento. Todavia, questiona-se se este não deveria ser um dos desígnios das AEC, enquanto política pública de apoio às famílias económica e culturalmente desfavorecidas.

Por último, o sucesso do programa AEC está particularmente comprometido pela inexistência de um sistema de avaliação amplo e rigoroso que, de forma sustentada, permita identificar as medidas necessárias para a sua melhor consecução.

Em síntese, os sentidos para os quais as AEC tendem a evoluir oscilam entre a dimensão social do programa e as preocupações da articulação e/ou diferenciação curricular. Alguns intervenientes no terreno tendem a privilegiar uma destas dimensões, o que constitui uma ameaça ao fundamental equilíbrio entre elas. No quadro de austeridade vigente teme-se que os vários condicionalismos decorrentes do recuo do Estado Social, nomeadamente ao nível do financiamento do programa, ampliem aquele desequilíbrio e acentuem o caráter assistencialista em prejuízo de uma política educativa pública de qualidade.

\section{BIBLIOGRAPHY}

BATEIRA, J. (2011), “A relação Estado-mercados na perspetiva do Institucionalismo Original”, Revista Crítica de Ciências Sociais, 95: 35-54.

BERNET, J.T. (1999) "A Educación Non Formal e a Cidade Educadora. Dúas Perspetivas (unha analítica e outra globalizadora do universo da Educación", Revista Galega do Ensino, n. 24: 199-221. 
COSME, A. e Trindade, R. (2007), Escola a Tempo inteiro: Escola para que te quero?, Porto: ProfEdições Lda.

DEMEUSE, M; Frandji, D; Greger, D \& Rochex, J.Y (dir.) (2008), L'éducation prioritaire en Europe: Conceptions, mises en oeuvre, débats, Paris: INRP.

DEN BESTEN, O. (2010), Visualising Social Divisions in Berlin: Children's After-School Activities in Two Contrasted City Neighbourhoods. Forum Qualitative Sozialforschung [On line], disponível em: http:// nbnresolving.de/urn:nbn:de: 0114-fqs1002353 [consultado 09/05/2012]

DOBERT, H., et al. (ed.) (2004), Conditions of school performance in seven countries, Múnster: Waxmann.

FIELD, S., Kuczera, M., \& Pont, B. (2007), No more failures: Ten steps to equity in education, Paris: OECD

FORMOSINHO, J. et al. (Org.) (1999), Comunidades educativas - Novos desafios à Educação Básica, Braga: Livraria Minho.

FORQUIN, J.C. (1993), Escola e cultura: as bases sociais e epistemológicas do conhecimento escolar, Porto Alegre: Artes Médicas.

LEITE, C. (2005), “A territorialização das políticas e das práticas educativas”, in Carlinda Leite (org.), Mudanças curriculares em Portugal. Transição para o século XXI, Porto, Porto Editora: 15-32. LEITE, C. (2006), "Políticas de currículo em Portugal e (im)possibilidades da escola se assumir como uma instituição curricularmente inteligente", Currículo sem Fronteiras, 6, n.o 2: 67-81.

LEITE, C. \& Pacheco, J. A. (2010), Para uma clarificação de conceitos que atravessam "A Prestação do Serviço Educativo", do processo de avaliação externa de escolas. Texto policopiado.

LIPOVETSKY, G. (1989), A Era do Vazio, Lisboa: Relógio D’Água.

MADUREIRA, C. et al. (2011), "Avaliação das atividades de enriquecimento curricular nas Escolas do $1^{\circ}$ Ciclo do Ensino Básico - Estudo de Caso nas áreas metropolitanas de Lisboa e Porto", Cadernos INA, n.ำ 48, Lisboa, INA Editora.

MARTINS, J. et al. (2006), As Autarquias e a Educação, Porto, Associação Nacional de Professores.

MOURAZ, A. et al. (2011), "School levels articulation: a relevant task for teachers' work”, in Teacher and Teacher education: Towards excellence in curriculum, pedagogy and leadership, Glasgow: University of Glasgow, ICET World Assembly: 38.

MUÑOZ, J. M. (2005), “Valores institucionales de la escuela pública: ideales que hay que precisar y políticas a realizar", in J. M. Muñoz et al., Sistema educativo y democracia. Alternativas para un sistema escolar democrático, Barcelona: Ediciones Octaedro: 9-36.

OCDE (2007), No More Failures: Ten Steps to Equity in Education. OECD publishing.

PACHECO, J. A. (1996), Currículo: teoria e práxis, Porto: Porto Editora.

PACHECO, J.A. \& VIEIRA, A. P. (2006), “Europeização do currículo. Para uma análise das políticas educativas e curriculares”, in A. F. Moreira \& J. A. Pacheco (Org.), Globalização e educação. Desafios para políticas e práticas, Porto: Porto Editora.

PEREIRA, A.V. (2010), “O Calcanhar de Aquiles do Programa AEC: A articulação curricular”, in Debater o Currículo e seus campos. Atas do IX Colóquio sobre Questões Curriculares/V Colóquio Luso-Brasileiro, Braga: CIE - IE/ U. Minho.

PIRES, C. (2007), “A Construção de Sentidos em Política Educativa: o caso da Escola a Tempo Inteiro”, Sísifo, Revista de Ciências da Educação, n. 4: 77- 86. 
REH, S. et al. (2011), Learning spaces without boundaries? Territories, power and how schools regulate learning [On line], disponível em http://dx.doi.org/10.1080/14649365.2011.54248, [consultado 09/05/2012].

ROLDÃO, M. C. (2008), "Prefácio", in M. Oliveira et al.,(orgs). Atividades de Enriquecimento Curricular: Relatório sobre a sua implementação no $1^{\circ}$ ciclo do Ensino Básico do concelho das Caldas da Rainha, Leiria: CIID e Folheto Edições e Design.

SCHNITTER, M. et al (s/d), Germany All-day Schooling in Düsseldorf, Germany, Education, economy and society. Better polices for better lives, OECD [On line], disponível em: http://www.oecd.org/edu/ educationeconomyandsociety/all-dayschoolingindusseldorfgermany.htm [consultado 09/05/2012].

\section{NOTES}

1. O auge da "Crise do Subprime" aconteceu em 2008.

2. O estudo Atividades de Enriquecimento Curricular: Qual o Sentido da Mudança? aguarda publicação em e-book pelo CIIE/FPCEUP.

3. Despacho 14 753/2005 de 05.07.2005 (Programa de generalização do Inglês nos $3^{\circ}$ e $4^{\circ}$ anos).

4. Idem

5. Ver, a este propósito, a nova estratégia da Comissão Europeia intitulada "Repensar a Educação", disponível em http://europa.eu/rapid/press-release_IP-12-1233_en.htm)

6. Cf. nota 2

7. Passagem timidamente ensaiada através do disposto no n.. 8 do Despacho Normativo n.. 13 A/2012 de 5 de junho de 2012

\section{ABSTRACTS}

No programa de Atividades de Enriquecimento Curricular pressupunha-se que o equilíbrio entre as suas finalidades - oferta universal e gratuita de atividades enriquecedoras do currículo do $1^{\circ}$ ciclo e criação de respostas sociais de apoio às famílias na ocupação lúdico-educativa pós escolar das crianças - resultava das condições da sua contratualização e implementação local. Não obstante estas se terem revelado insuficientes, face ao atual e progressivo retraimento da intervenção do Estado, este precário equilíbrio tenderá a debilitar-se em favor de dimensões assistencialistas. O texto reflete sobre esta política pública, a partir dos resultados do estudo realizado em 2009-10, no Porto, pelos Observatório da Vida nas Escolas e Observatório da Cidade Educadora do CIIE/ FPCE-UP.

Curricular enrichment program (all day schooling program) seeks for the balance between two different aims: its universal and free offer of a set of activities that enriches first school level curriculum and the social support to families that program ensures. This balance, one's believe, is a result of program conditions related to contracts and local implementation. Recently, due to economic crisis and Government budget diminish, program was affected and tends to favors social support over curriculum improvement. Text reflects on all day schooling program policies 
and mobilizes data coming from a research conducted during 2009-10 by Life Schools' Observatory and Educating Cities' Observatory.

Le programme de l'enrichissement curriculaire a cherché le juste équilibre entre les deux finalités qu'il a poursuit: enrichir les apprentissages des élèves, de tous les élèves du premier degré, et répondre aux besoins de ses familles. Les contrats que ont été signés et la dimension locale du programme ont contribué pour cet équilibre la. Mais, maintenant, a cause de la crise économique, l'État a réduit l'effort pour maintenir le programme, qui risque de se réduire à dimension de la solidarité sociale. Ce texte-la s'occupe de réfléchir sur ces politiques publiques, et mobilise pour ce but les donnes recueillis pendant l'année de 2009/2010 par l'Observatoire de la vie des écoles et par l'Observatoire de la Cité Educatrice.

\section{INDEX}

Keywords: public policy, full time school, curriculum enrichment, measure of social support equality

Palavras-chave: políticas públicas, escola a tempo inteiro, enriquecimento curricular, medida de apoio social, promoção da igualdade

Mots-clés: politiques publiques, école à plein temps, enrichissement des programmes d'études, mesure de soutien égalité sociale

\section{AUTHORS}

\section{ANA MOURAZ}

CIIE, Faculdade de Psicologia e Ciências da Educação, Universidade do Porto anamouraz@fpce.up.pt

\section{ANA VALE}

CIIE, Faculdade de Psicologia e Ciências da Educação, Universidade do Porto anavalepereira@gmail.com

\section{JORGE MARTINS}

CIIE, Faculdade de Psicologia e Ciências da Educação, Universidade do Porto jorgemartins51@gmail.com 